\section{Brazil promotes aviation biofuels}

The drive to produce biofuels that are suitable for aviation is starting to look promising (see go.nature.com/ujv5ne). For instance, the state government of Minas Gerais in Brazil has put in place policies to stimulate the cultivation, extraction and processing of the native macaw palm (Acrocomia aculeata), a potentially sustainable source of oil for producing biokerosene.

This tree can produce up to 6,200 kilograms of oil per hectare (see T. P. Pires et al. Ind. Crops Prod. 44, 200-210; 2013) and can sequester as much as 4-5 times more carbon than other afforestation species such as Eucalyptus camaldulensis (see H. Suganuma et al. J. Arid Land Stud. 22, 69-72; 2012).

To safeguard forests, macaw palms will be planted only on existing pastureland (estimated at 170 million hectares in 2010). Oil production from macaw palms, which could exceed the size of today's global palmoil market, does not need to compromise food production or natural ecosystems (see go.nature.com/67tfia). The trees can be cultivated next to agricultural crops and their extensive canopy cover provides fauna with food and shelter, helping to restore biodiversity that has been lost by forest clearance.

Éder Cristian Malta de Lanes, Paulo Mafra de Almeida Costa, Sérgio Yoshimitsu Motoike Federal University of Viçosa, Minas Gerais, Brazil. edercml@gmail.com

\section{Reassess Chinese research awards}

China's research-award system needs reform if it is to encourage future advances in science and technology. We believe that a move away from current government schemes - which mainly recognize large technological projects - towards non-governmental awards for individual researchers would boost academic competition and be more effective in the long term.

Non-governmental award schemes in China do not carry the same prestige as they do in Western countries. The Chinese government gives national prizes every year to about 280 research projects and six individual researchers, on average, and regional prizes to a further 3,000 projects. Scientific societies, which are mostly affiliated with the government and led by retired government officials, offer annual prizes for some 10,000 projects. Most of these awards are intended to motivate technological invention and application. Less than $5 \%$ of prizes are bestowed for research in the natural sciences.

In our view, the Chinese government should deregulate awards related to technological inventions and applications and allow the prizes to be determined by the market. China's scientific societies also need reform to give them more authority and greater autonomy, so that their research awards can focus on academic achievements and be more influential.

Yuan-Feng Wang, Hui-Bing Xie Beijing Jiaotong University, China.

cyfwang@bjtu.edu.cn

\section{Cookstoves: clean up fuel on two fronts}

Contrary to the impression you convey (see Nature 509, 533; 2014) biomass-burning cooking technology is advancing steadily. Stoves are now more efficient and emit much less smoke, and will remain popular as long as users can access biomass, such as wood and dung, at zero direct cost. Efforts must therefore continue to make clean fuels available and available fuels clean.

In trials of new types of biomass-burning stove
- including the trial covered by the 2012 report you mention - one factor contributing to the apparent negative outcome is promoters' use of the term 'improved' to market new stoves, often without justification. This has led to the conclusion that the 'improvements' have not worked. Genuine improvements can stem only from systematic testing and assessment. Moreover, randomized controlled trials of health interventions need to follow strict criteria (see, for example, K. R. Smith et al. Lancet 378, 1717-1726; 2011).

This autumn, the Global Alliance for Clean Cookstoves in Washington DC and ISO, the International Organization for Standardization, are due to finalize the first health-based emissions standards for biomass stoves. These are informed by the World Health Organization's upcoming Indoor Air Quality Guidelines. No longer will funders, non-governmental organizations, the private sector, the media and researchers have to rely on vague and unsubstantiated descriptors to judge stove performance.

Kirk R. Smith University of California, Berkeley, USA. krksmith@berkeley.edu

\section{Cookstoves: a design popular in Peru}

Conversion to clean-energy fuel is a priority for cooking among Peru's rural communities. This is for two reasons: because of the adverse health effects of indoor smoke from biomass-burning stoves (see Nature 509, 548-551; 2014) and because using tropical hardwoods as fuel is accelerating deforestation in the Amazon.

The only viable source of clean fuel for rural communities in the Peruvian Amazon is natural gas, which has to be extracted and transported across the Andes, imposing prohibitively high running costs.

A pyrolysis cooking stove offers another solution. Its combustion design (see go.nature.com/e7j8q1) makes it superior to the biomassburning stoves you describe. For example, it cooks faster than an open fire but consumes half the amount of wood, generates half the smoke and can run on lowgrade fuel such as small twigs and leaf litter.

At US\$180 per unit, it is costly compared with the $\$ 15$ stoves that you discuss, but the price incorporates training, monitoring and education to ensure that the stove is properly used. It is also a simple matter to convert these stoves to burn natural gas, should that become more economically viable.

Kaysara Khatun Autonomous University of Barcelona (UAB), Bellaterra, Spain.

Brenton Ladd Scientific University of the South, Lima, Peru. brenton.ladd@gmail.com

\section{Longitude Prize now an objective decision}

Martin Rees writes that John Harrison "came closest to receiving the reward money" offered in the 1714 Longitude Act (Nature 509, 401; 2014). This description conceals a long and painful battle between astronomers and those who argued that Harrison should be awarded the prize for his marine chronometer, designed to determine the longitude of a ship's position by using existing tables.

The astronomers of the day claimed that watching Jupiter's moons, as suggested by Galileo, was the scientific solution. But in practice, this 'astronomic' solution would not work under a cloudy sky.

Today, by contrast, the winner of the 2014 Longitude Prize, who we now know will be working on antibiotic resistance, will be "decided objectively - as in athletics", as Rees points out. Carl G. Ribbing Uppsala University, Sweden. cg.ribbing@angstrom.uu.se 